\title{
The impact of the oral condition of children with sickle cell disease on family quality of life
}

\author{
Maria Luiza da Matta Felisberto \\ FERNANDES(a) \\ Ichiro KAWACHI (b) \\ Patrícia CORRÊA-FARIA(a) \\ Saul Martins PAIVA(a) \\ Isabela Almeida PORDEUS(a)
}

(a) Universidade Federal de Minas Gerais UFMG, School of Dentistry, Department of Pediatric Dentistry and Orthodontics, Belo Horizonte, MG, Brazil.

(b) Harvard University, School of Public Health, Department of Social and Behavioral Sciences, Boston, MA, USA.

Declaration of Interests: The authors certify that they have no commercial or associative interest that represents a conflict of interest in connection with the manuscript.

Corresponding Author: Maria Luiza da Matta Felisberto Fernandes E-mail: marialuizadamatta@gmail.com

DOI: 10.1590/1807-3107BOR-2016.vol30.0021

Submitted: Sep 09, 2015

Accepted for publication: Oct 01, 2015

Last revision: Nov 09, 2015

\begin{abstract}
The aim of this study was to assess the impact of oral conditions of children with sickle cell disease (SCD) on their parents' quality of life (QoL). A cross-sectional study was performed with parents of outpatients suffering from SCD at a hematology referral center in Belo Horizonte, MG. A qualified dentist performed an intraoral exam. The Family Impact Scale (FIS) was used to assess the parents' perception of QoL. The parents answered some questions regarding sociodemographic and medical information about their children. The $\mathrm{dmft} / \mathrm{DMFT}$ score, DAI, gum bleeding and SCD severity were evaluated in terms of their impacts on the overall mean FIS scores and subscale scores. The chance of more frequent impacts was greater in parents of adolescents $(\mathrm{OR}=2.04 ; 95 \% \mathrm{CI}=1.2,3.4)$ than of younger children. Dental caries ( $\mathrm{dmft} / \mathrm{DMFT} \geq 1)$ had a negative impact on the QoL of parents of younger children and adolescents $(\mathrm{p}<0.05$ and $\mathrm{p}<0.01$, respectively). Among the parents of younger children, dental caries and SCD severity significantly affected the subscales for parental activities (PA) and parental emotions (PE) $(\mathrm{p}<0.01, \mathrm{p}<0.05$, respectively). Among parents of adolescents, dental caries (DMFT) and severe malocclusion adversely affected the PE and PA subscales ( $p<0.01, p<0.05$, respectively). SCD severity affected the overall FIS score among young children's parents $(p<0.05)$. In conclusion, dental caries, age and SCD severity were associated with a negative impact on the QoL of parents of children with SCD
\end{abstract}

Keywords: Anemia, Sickle Cell; Quality of Life; Parents.

\section{Introduction}

Sickle cell anemia is a genetic disease that leads to polymerization of hemoglobin in situations of low oxygen tension, causing episodes of pain and other systemic complications, starting about the age of 6 months. ${ }^{1}$ The severity of clinical manifestations depends on the genotype and the environment. ${ }^{1}$ The homozygous form (HBSS) is the most severe genotype. ${ }^{2}$

Oral complications have been reported but these are not as common as other complications. Mandibular osteomyelitis, mandibular nerve anesthesia, glossitis and gingival enlargement, pallor of mucous membranes, and asymptomatic pulpal necrosis have all been associated with SCD. ${ }^{3}$ Increased demand for erythropoiesis may cause compensatory expansion of the marrow spaces of the craniofacial bones. This can lead to maxillary 
protrusion with the flaring of maxillary incisor teeth, thin border of the mandible, and increased prominence of zygomatic and parietal bones. Conclusive evidence is lacking on the dental caries experience of children with sickle cell disease (SCD). ${ }^{4}$ The main reason for the relationship between dental caries and SCD seems to be an association with poor hygiene behavior. ${ }^{5}$

Parents tend to be the primary caregivers of children with SCD, by offering emotional support. ${ }^{6}$ The emotional well-being of parents is fundamental to promoting a good quality of life (QoL) and the health maintenance of children with SCD. ${ }^{6,7}$ However, the task of looking after someone without being properly prepared can cause personal and family conflicts and even stress, embarrassment, fatigue and depression for caregivers, and may consequently influence their QoL. ${ }^{8}$ Studies of parents of children with SCD have found that these parents have a poor QoL, especially regarding self-esteem, physical functioning and overall perception of health. These impacts may be even higher among parents than among children with SCD. ${ }^{9}$

The QoL of parents can also be affected by the oral health problems experienced by children. Periodontal, orthodontic and orofacial conditions can all impact the QoL of parents of healthy children. ${ }^{10}$ Most investigations into the impact of oral conditions on QoL involve only healthy children. ${ }^{11}$ There are only sparse studies assessing the oral health-related QoL of children with sickle cell anemia, ${ }^{4}$ and there is no research on the impact of these children's oral health on the QoL of parents.

Therefore, the aim of this study was to assess the impact of the oral conditions of children with SCD on caregivers' QoL.

\section{Methodology}

The Human Ethics Committee of the Hematology Foundation Center of Minas Gerais (Fundação Centro de Hematologia e Hemoterapia de Minas - Hemominas) approved this study. The participants' legal guardians signed an informed consent form.

\section{Study population and data collection}

A cross-sectional study was conducted among children diagnosed with SCD, residing in the metropolitan region of Belo Horizonte, aged 8 to 14 years, sampled from the Hemominas patient registry in Belo Horizonte, Minas Gerais, Brazil. Parents (or alternatively, the individual with the greatest responsibility for caring for the patient during the course of the disease) were invited to participate in the study.

The inclusion criteria for the children in the sample were: not suffering from a painful crisis at the time of the survey, having no medical conditions other than SCD, having had no emergency dental appointment in the past three months, willingness to undergo a dental clinical exam, and no intellectual disability. There were a total of 196 children aged 8 to 14 years, residing in the metropolitan region of Belo Horizonte, who were receiving services provided by Hemominas, in the year 2012. ${ }^{12}$ Of these, 72 were not included in the study ( 3 died and 69 had mental disabilities or were undergoing dental treatment). A total of 106 parents and their children agreed to participate in the research (response rate of $85.5 \%$ ). Eighteen parent-child dyads declined to participate in the study.

The research team was made up of a dentist and four dental students. Prior to the fieldwork, the examiner underwent a calibration and training exercise for diagnosing oral diseases. Calibration was performed by the clinical examination of children who were not included in the main study. Data analysis involved the calculation of Kappa coefficients $(\mathrm{K}=0.89$ for interexaminer and 0.92 for intraexaminer agreement). The questionnaires were answered by the parents of these children, and the correlation of responses to the interviews was verified by test-retest $($ Kappa value $=0.82)$. The recalibration of clinical exams carried out every 2 months, consistently, achieved a Kappa value of agreement $\geq 0.87$.

The intraoral exam was performed on each patient using a disposable mirror, CPI probes and gauzes, according to recommendations for oral epidemiological surveys by the World Health Organization (WHO). ${ }^{13}$ The $\mathrm{WHO}^{13}$ standards were used to evaluate the following: DMFT index, dental aesthetic index (DAI) and gingival index.

The DAI assesses the aesthetic aspects of dental occlusion and the need for orthodontic treatment according malocclusion severity. The following conditions were evaluated: absence of upper and lower teeth, followed by diastema or crowding 
in the upper and lower anterior segments, lower anterior overjet, incisal overjet, open bite and molar anteroposterior ratio. After clinical evaluation, an equation was developed to calculate the values obtained. It provided four possible outcomes: mild malocclusion (DAI $\leq 25)$, defined malocclusion $(\mathrm{DAI}=26-30)$, severe malocclusion $(\mathrm{DAI}=31-35)$ and very severe or disabling malocclusion $(\mathrm{DAI} \geq 36) \cdot{ }^{13}$

The dental exams and interviews were carried out in private rooms at Hemominas during the day, under natural light, from January to July 2012. On the day of the dental clinical exam, the parents/caregivers were invited to answer some questions regarding sociodemographic and medical information about their children, and the Family Impact Scale (FIS). SCD severity was determined based on the occurrence of pain episodes, hospitalizations and the need for blood transfusion in the thirty-day period prior to the survey. The presence of diseases associated with SCD reported by parents and confirmed by the child's medical records was also considered.

\section{Family Impact Scale}

The FIS is an instrument that evaluates the impact of a child's oral condition on family life. It is one of the four questionnaires comprising the COHQoL instrument developed by Jokovic et al. ${ }^{14}$ It was validated in the Brazilian Portuguese language by Goursand et al., ${ }^{15}$ and was shown to have good psychometric properties. It consists of 14 items divided into four subscales: parental / family activity (PA), parental emotions (PE), family conflict (FC), and financial burden (FB). The questions refer only to the frequency of events in the 3 months prior to completion of the instrument. The items have five response options: 'never $=0$ ', 'once or twice $=1$ ', 'sometimes $=2$ ', 'often $=3$ ', and 'every day or almost every day $=4$ '. The number of 'don't know' responses was counted, but they were excluded from the total FIS score for each patient. The total FIS scores and the scores for the individual subscales were calculated as a simple sum of the response codes.

\section{Data analysis}

Descriptive analyses were conducted on the children's sociodemographic, oral and clinical characteristics. The parents' responses to the FIS were described in terms of lower frequency of impacts (never, once/twice, sometimes) and higher frequency of impacts (often, every day/almost every day). The odds ratio (OR) of the impacts was calculated for each FIS item, comparing younger children and adolescents, and for the total FIS. The Fisher test was used when it was not possible to calculate the OR.

The impacts of each oral condition on the overall mean FIS scores and subscale scores were evaluated - DMFT, DAI, gum bleeding and SCD severity. The Shapiro-Wilk test was used to perform this initial exploratory analysis. It assessed the normality of the distribution of values. After this procedure, associations were tested between dependent and independent variables, by means of univariate analysis (Mann-Whitney test, Fisher's exact test and chi-square test). In addition, both simple and multivariable linear regression was performed to determine significant associations between FIS and predictors.

\section{Results}

A total of 56 children and 50 adolescents were examined. The mean age was $8.9(\mathrm{SD}=0.9)$ among children and $12.0(\mathrm{SD}=1.1)$ among adolescents; $55.3 \%$ $(n=31)$ of children and $60.0 \%$ of adolescents were boys. The mean values $\mathrm{dmft} / \mathrm{DMFT}$ for children and adolescents were $1.3(\mathrm{SD}=2.0)$ and $1.4(\mathrm{SD}=1.9)$, respectively. The prevalence values of gingival bleeding for children and adolescents were 16\% $(n=9)$ and $54 \%(n=27)$, respectively. The mean values of DAI for children and adolescents were $32.2(\mathrm{SD}=10.6)$ and $31.7(\mathrm{SD}=10.7)$, respectively.

All the parents interviewed in this study $(n=106)$ completed the FIS, and no questionnaire was excluded from data analysis owing to lack of data. Most of the questionnaires were answered by mothers $(75 \%$ from the younger children's group and $82 \%$ from the adolescent group). There was no significant difference between the FIS mean reported by mothers 6.1 $(\mathrm{SD}=6.6)$ and by fathers/caregiver's $3.0(\mathrm{SD}=4.2)$ (results not shown).

Table 1 displays the distribution of responses to the FIS, according to lower frequency of impacts (never, once/twice, sometimes) and higher frequency of impacts (often, everyday/almost every day), according to each 
Table 1. Parents' responses to the FIS (Family Impact Scale) on the survey.

\begin{tabular}{|c|c|c|c|c|}
\hline \multirow{3}{*}{ Items of the FIS } & \multicolumn{2}{|c|}{ Children's parents } & \multicolumn{2}{|c|}{ Adolescents' parents } \\
\hline & $\begin{array}{l}\text { Never/once-twice/ } \\
\text { sometimes }\end{array}$ & Often/every day & $\begin{array}{l}\text { Never/once-twice/ } \\
\text { sometimes }\end{array}$ & Often/every day \\
\hline & n (\%) & n (\%) & n (\%) & n (\%) \\
\hline \multicolumn{5}{|l|}{ Parental / Family activities (PA) } \\
\hline FIS 1 - Have you or has the other parent taken time off work? ${ }^{\mathrm{A}}$ & $55(100)$ & $0(0)$ & $48(96)$ & $2(4)$ \\
\hline FIS 2 - Has your child required more attention from you or the other parent? & $50(91)$ & $5(9)$ & $45(90)$ & $5(10)$ \\
\hline $\begin{array}{l}\text { FIS } 3 \text { - Have you or has the other parent had less time for yourself or } \\
\text { other family members? }\end{array}$ & $53(96)$ & $2(4)$ & $49(98)$ & $1(2)$ \\
\hline FIS 4 - Has your sleep or that of the other parent been disrupted? ${ }^{A}$ & $56(100)$ & $0(0)$ & $48(98)$ & $1(2)$ \\
\hline FIS 5 - Have family activities been interrupted? ${ }^{A}$ & $54(98)$ & $1(2)$ & $49(100)$ & $0(0)$ \\
\hline \multicolumn{5}{|l|}{ Parental emotions (PE) } \\
\hline FIS 6 - Have you or has the other parent been upset? & 49 (89) & $6(11)$ & $41(84)$ & $8(16)$ \\
\hline FIS 7 - Have you or has the other parent felt guilty? & $55(98)$ & $1(2)$ & $45(94)$ & $3(6)$ \\
\hline $\begin{array}{l}\text { FIS } 8 \text { - Have you or has the other parent worried that your child will } \\
\text { have fewer life opportunities? }\end{array}$ & $50(91)$ & $5(9)$ & $40(82)$ & $9(18)$ \\
\hline FIS 9 - Have you felt uncomfortable in public places? & $55(98)$ & $1(2)$ & $45(94)$ & $3(6)$ \\
\hline \multicolumn{5}{|l|}{ Family conflict (FC) } \\
\hline FIS 10 - Has your child argued with you or the other parent? & $53(96)$ & $2(4)$ & $46(92)$ & $4(8)$ \\
\hline FIS 11 - Has your child been jealous of you or other family members? ?A* $^{A *}$ & $53(100)$ & $0(0)$ & $44(92)$ & $4(8)$ \\
\hline $\begin{array}{l}\text { FIS } 12 \text { - Has your child's condition caused disagreement or conflict in } \\
\text { the family? }\end{array}$ & $56(100)$ & $0(0)$ & $50(100)$ & $0(0)$ \\
\hline FIS 13 - Has your child blamed you or the other parent? ${ }^{A}$ & $55(100)$ & $0(0)$ & $49(100)$ & $0(0)$ \\
\hline \multicolumn{5}{|l|}{ Financial burden (FB) } \\
\hline FIS 14 - Has your child's condition caused financial difficulties for your family? & $53(96)$ & $2(4)$ & $46(92)$ & $4(8)$ \\
\hline FIS overall & $748(97)$ & $25(3)$ & $645(94)$ & $44(6)$ \\
\hline
\end{tabular}

${ }^{A} p$-value of Fisher's exact test.

${ }^{*} p<0.05$.

item. The item "Have you or has the other parent been upset?" was most frequently reported by parents of younger children. Concern about the child having fewer opportunities in life was the item that most often worried parents of adolescents. Moreover, the item of parental concern about the child being more jealous of them or of other family members was significantly greater among parents of adolescents $(\mathrm{p}<0.05)$. Twenty-five $(3 \%)$ of the younger children's parents, and $44(6 \%)$ of the adolescents' parents reported higher frequency of negative impacts on QoL, that is, a score of 3 and 4 (often, every day/almost every day) on the total FIS.

Table 2 contains the mean, the standard deviation, the median and the range observed for the total FIS score and for each subscale.

Table 3 shows the mean difference (in percentage) between the total FIS and subscales, according to specific clinical conditions. Dental caries (DMFT $\geq 1$ ) was associated with a poorer QoL of parents of both younger children and adolescents $(\mathrm{p}<0.05$ and $p<0.01$, respectively). Considering the effect of each subscale on the parents' QoL, dental caries (DMFT) was associated with negative impacts on parental activities (PA) and parental emotions (PE) among parents of younger children $(p<0.01$ and $p<0.05$, respectively). Dental caries (DMFT) and severe malocclusion were associated with a negative impact on the PE and PA subscales ( $p<0.01$ and $p<0.05$, respectively) among parents of adolescents. In addition, SCD severity was associated with a negative impact on the overall FIS $(p<0.05)$ among parents of younger children.

The multivariate adjusted model shows that age, DMFT and SCD severity were correlated with parental QoL $(\mathrm{p}<0.05)$ (Table 3). The final multivariate adjusted model is comprised of three covariates: dental caries (DMFT), age and SCD severity. The model accounts for $20 \%$ of the negative impact on the parents' QoL $(\mathrm{R}$ square $=20 \% ; \mathrm{F}=3.44 ; \mathrm{p}=0.004)($ Table 4$)$. 
Table 2. Mean, standard deviation, median, and range observed in the FIS (Family Impact Scale).

\begin{tabular}{|c|c|c|c|}
\hline Items of the FIS & Mean (SD) & Median & Range observed \\
\hline Total FIS & $5.44(6.29)$ & 3 & $0-36$ \\
\hline Parental/family activities (PA) & $2.01(2.71)$ & 1 & $0-14$ \\
\hline FIS 1 - Have you or has the other parent taken time off work? & $0.34(0.78)$ & 0 & $0-4$ \\
\hline FIS 2 - Has your child required more attention from you or the other parent? & $0.68(1.14)$ & 0 & $0-4$ \\
\hline FIS 3 - Have you or has the other parent had less time for yourself or other family members? & $0.53(0.92)$ & 0 & $0-3$ \\
\hline FIS 4 - Has your sleep or that of the other parent been disrupted? & $0.28(0.67)$ & 0 & $0-3$ \\
\hline FIS 5 - Have family activities been interrupted? & $0.19(0.59)$ & 0 & $0-3$ \\
\hline Parental emotions (PE) & $2.19(2.78)$ & 1 & $0-12$ \\
\hline FIS 6 - Have you or has the other parent been upset? & $0.86(1.26)$ & 0 & $0-4$ \\
\hline FIS 7 - Have you or has the other parent felt guilty? & $0.43(0.90)$ & 0 & $0-4$ \\
\hline FIS 8 - Have you or has the other parent worried that your child will have fewer life opportunities? & $0.70(1.23)$ & 0 & $0-4$ \\
\hline FIS 9 - Have you felt uncomfortable in public places? & $0.24(0.79)$ & 0 & $0-4$ \\
\hline Family conflict (FC) & $0.86(1.68)$ & 0 & $0-8$ \\
\hline FIS 10 - Has your child argued with you or the other parent? & $0.35(0.94)$ & 0 & $0-4$ \\
\hline FIS 11 - Has your child been jealous of you or other family members? & $0.29(0.76)$ & 0 & $0-3$ \\
\hline FIS 12 - Has your child's condition caused disagreement or conflict in the family? & $0.11(0.46)$ & 0 & $0-2$ \\
\hline FIS 13 - Has your child blamed you or the other parent? & $0.12(0.47)$ & 0 & $0-2$ \\
\hline Financial burden (FB) & $0.35(0.89)$ & 0 & $0-4$ \\
\hline FIS 14 - Has your child's condition caused financial difficulties for your family? & $0.35(0.89)$ & 0 & $0-4$ \\
\hline
\end{tabular}

\section{Discussion}

The following factors were evaluated in this study: the impact of children's dental caries (DMFT), malocclusion (DAI), gingival bleeding and SCD severity on parents' QoL. To the best of our knowledge, this is the first study focusing on these aims for families of children with SCD, by using the Brazilian version of the FIS after its validation. Children's malocclusion and gingival bleeding were not associated with parents' QoL. Children's DMFT, age and SCD severity were associated with a negative impact on the parents' QoL.

Table 3. Comparative means (\%) between clinical condition categories for the same FIS subscale.

\begin{tabular}{|c|c|c|c|c|c|c|c|c|c|c|}
\hline & \multicolumn{8}{|c|}{ FIS subscale means (SD) } & \multirow{2}{*}{\multicolumn{2}{|c|}{ Total FIS }} \\
\hline & \multicolumn{2}{|c|}{$\begin{array}{l}\text { Parental/family } \\
\text { activities (PA) }\end{array}$} & \multicolumn{2}{|c|}{ Parental Emotions (PE) } & \multicolumn{2}{|c|}{ Family conflicts (FC) } & \multicolumn{2}{|c|}{ Financial burden (FB) } & & \\
\hline & Children & Adolescents & Children & Adolescents & Children & Adolescents & Children & Adolescents & Children & Adolescents \\
\hline \multicolumn{11}{|l|}{ DMFT } \\
\hline Caries free & $0.05(0.09)$ & $0.10(0.17)$ & $0.07(0.12)$ & $0.13(0.20)$ & $0.03(0.08)$ & $0.05(011)$ & $0.10(0.23)$ & $0.11(0.27)$ & $0.05(0.07)$ & $0.10(0.15)$ \\
\hline $\mathrm{DMFT} \geq 1$ & $0.11(0.11)^{* *}$ & $0.15(0.15)$ & $0.14(018)$ & $0.25(0.18)^{* *}$ & $0.03(0.07)$ & $0.10(0.15)$ & $0.05(0.14)$ & $0.10(0.24)$ & $0.09(0.09)^{*}$ & $0.16(0.11)^{* *}$ \\
\hline \multicolumn{11}{|l|}{ DAl } \\
\hline Light Malocclusion & $0.10(0.11)$ & $0.08(0.16)$ & $0.11(0.17)$ & $0.17(0.18)$ & $0.03(0.08)$ & $0.04(0.10)$ & $0.07(0.20)$ & $0.09(0.27)$ & $0.08(0.09)$ & $0.10(0.13)$ \\
\hline Severe Malocclusion & $0.06(0.09)$ & $0.16(0.15)^{*}$ & $0.08(0.12)$ & $0.21(0.20)$ & $0.03(0.07)$ & $0.11(0.14)$ & $0.08(0.19)$ & $0.11(0.23)$ & $0.05(0.07)$ & $0.16(0.13)^{*}$ \\
\hline \multicolumn{11}{|l|}{ Gingival Bleeding } \\
\hline No & $0.06(0.09)$ & $0.11(0.18)$ & $0.09(0.13)$ & $0.17(0.19)$ & $0.04(0.08)$ & $0.07(0.13)$ & $0.07(0.19)$ & $0.06(0.23)$ & $0.06(0.07)$ & $0.11(0.15)$ \\
\hline Yes & $0.16(0.15)$ & $0.13(0.15)$ & $0.17(0.23)$ & $0.20(0.20)$ & $0.00(0.00)$ & $0.08(0.13)$ & $0.11(0.22)$ & $0.14(0.27)$ & $0.12(0.12)$ & $0.14(0.12)$ \\
\hline \multicolumn{11}{|l|}{ SCD Severity } \\
\hline Low level & $0.06(0.08)$ & $0.12(0.17)$ & $0.08(0.14)$ & $0.17(0.19)$ & $0.02(0.07)$ & $0.07(0.13)$ & $0.08(0.21)$ & $0.10(0.25)$ & $0.06(0.07)$ & $0.12(0.14)$ \\
\hline High level & $0.13(0.14)$ & $0.14(0.14)$ & $0.15(0.17)^{*}$ & $0.22(0.19)$ & $0.05(0.07)$ & $0.09(0.13)$ & $0.04(0.13)$ & $0.10(0.25)$ & $0.12(0.11)^{*}$ & $0.15(0.12)$ \\
\hline
\end{tabular}


Table 4. Parent's responses to the FIS (Family Impact Scale) in the survey $(n=106)$.

\begin{tabular}{|c|c|c|c|c|}
\hline \multirow{2}{*}{ Covariate } & \multicolumn{2}{|c|}{ Multivariate analysis } & \multicolumn{2}{|c|}{ Multivariate model } \\
\hline & $\beta$ & SE & $\beta$ & SE \\
\hline \multicolumn{5}{|c|}{ Individual characteristics } \\
\hline Age & 1.08 & $0.47^{*}$ & 1.07 & $0.43^{* *}$ \\
\hline Gender & -1.25 & 1.25 & CNS & \\
\hline Caregiver mother & 1.64 & 1.54 & CNS & \\
\hline Income & -0.001 & 0.001 & CNS & \\
\hline \multicolumn{5}{|l|}{ Clinical conditions } \\
\hline DAI & 0.025 & 0.06 & CNS & \\
\hline DMFT & 0.67 & $0.31^{*}$ & 0.66 & $0.30^{*}$ \\
\hline Gingival bleeding & -0.10 & 1.45 & CNS & \\
\hline SCD Severity & 0.53 & $0.28^{*}$ & 0.54 & $0.27^{*}$ \\
\hline $\mathrm{R}^{2}$ & $20 \%$ & & $20 \%$ & \\
\hline $\mathrm{F}$ & 2.55 & & 3.44 & \\
\hline$p$-value & 0.01 & & 0.004 & \\
\hline
\end{tabular}

CNS: Covariate not selected for the final model ( $p$-value $>0.05$ ).

$* p<0.05$

${ }^{* *} p<0.01$.

The chance of more frequent impacts was greater in relation to the adolescents' parents $(\mathrm{OR}=2.04$; $95 \% \mathrm{CI}=1.2,3.4)$ than to the younger children's parents. The impact of caries on parental QoL may be linked to concerns about aesthetic appearance. ${ }^{11}$ Moreover, it is expected that the children may require more attention from the parent to relieve discomfort resulting from dental caries. ${ }^{16}$ The prevalence of caries is related to sociobehavioral determinants, and is generally connected to lifestyle factors and age..$^{16,17,18}$

Age is associated with greater severity of sickle cell disease, and the greater severity of SCD requires greater attention from parents. ${ }^{19,20}$ Thus, it may represent a greater impact on the family's QoL. ${ }^{20}$ The severity of SCD may place additional pressure on the caregiver. A study conducted in Brazil evaluated the burden and QoL of 37 caregivers of patients with sickle cell anemia. The caregivers with a greater burden had a worse QoL. ${ }^{7}$ Lower QoL scores were also seen in subscales regarding depressed mood, daily activity and vitality in 54 caregivers of children with SCD in the Netherlands. ${ }^{21}$

Considering the perceptions on oral QoL, greater agreement was observed between parents and adolescents than between parents and younger children. ${ }^{22,23,24}$ It is believed that an older age improves communication between the parent and the child. ${ }^{25}$
Parental concern about the jealousy of other family members was significantly greater among parents of adolescent ( $p<0.05)$, although this item was not frequently endorsed on the FIS. Adolescence heightens the difficulty of adaptation and adjustment needed by SCD patients, ${ }^{26}$ this factor may have contributed to enhancing the perception of parents of adolescents.

The DMFT index showed a negative impact on the parental activities (PA) subscale and the overall FIS among younger children. Abanto et al. ${ }^{11}$ assessed the impact of healthy children's dental caries (DC) on 219 parents of children age 5 and 6 years old, using the same instrument - Family Impact Scale (FIS) - and observed similar results. The severity of children's DC had a negative impact on parents' QoL. Other studies with healthy children and parents have also indicated that DC results in a loss of family activity days or workdays for caregivers who have to stay home to take care of their child or who spend time and money on acquiring dental care services. ${ }^{27,28}$ In addition, the DMFT index showed a negative impact on the parental emotions (PE) subscale and the overall FIS in the adolescent group. Better parent-child communication can enable parents to participate more in monitoring the health and development of their children.$^{25}$ Likewise, the severity of children's malocclusion was associated with a negative impact 
on FIS among the parents of adolescents. Malocclusion among younger children was not negatively associated with the FIS subscales. Probably, severe malocclusion at younger ages has not yet been established. ${ }^{29,30}$ Dental malocclusion may cause functional disorders or disabilities other than aesthetic discomfort. ${ }^{29,30} \mathrm{It}$ stands to reason that parents of children with SCD can also perceive this impact. Despite the negative impact of malocclusions in adolescents, when evaluating specific items of the FIS, the final multivariate model showed that only an increase in DMFT produced a negative impact on the parents' QoL.

Age and SCD severity were associated with a negative impact on the parents' QoL. This result confirmed other previous studies conducted with SCD children, which showed that the longer the duration of care, the worse the QoL of SCD caregivers. ${ }^{6,7}$ In addition, disease complications may interact with the caregiver's ability to manage proper functioning of the family and QoL. A convenience sample composed of parents of children withSCD from a hospital center (Hemominas) was used to conduct this study. At the time of the interview, the parents were not seeking preventive and/or restorative treatment for their children. Thus, a limitation of this study was the extrapolation of the results to the general

\section{References}

1. Smith WR, Scherer M. Sickle-cell pain: advances in epidemiology and etiology. Hematology Am Soc Hematol Educ Program. 2010;2010(1):409-15. doi:10.1182/asheducation-2010.1.409

2. Benton TD, Ifeagwu JA, Smith-Whitley K. Anxiety and depression in children and adolescents with sickle cell disease. Curr Psychiatry Rep. 2007;9(2):114-21. doi:10.1007/s11920-007-0080-0

3. Kelleher M, Bishop K, Briggs P. Oral complications associated with sickle cell anemia: a review and case report. Oral Surg Oral Med Oral Pathol Oral Radiol Endod. 1996 Aug;82(2):225-8. doi:10.1016/S1079-2104(96)80261-7

4. Ralstrom E, Fonseca MA, Rhodes M, Amini H. The impact of sickle cell disease on oral health-related quality of life. Pediatr Dent. 2014;36(1):24-8.

5. Passos CP, Santos PR, Aguiar MC, Cangussu MC, Toralles $\mathrm{MB}$, Silva MC, et al. Sickle cell disease does not predispose to caries or periodontal disease. Spec Care Dentist. 2012;32(2):55-60. doi:10.1111/j.1754-4505.2012.00235.x population. For this reason, future studies should be carried out to assess the impact of children's oral diseases and disorders on parents' QoL in multicenter studies. Another limitation was that we did not compare the results with a control group of parents of healthy children. Studies comparing the healthrelated QoL of parents with SCD children versus healthy children showed lower QoL scores in parents of SCD children in all dimensions. ${ }^{21}$

\section{Conclusion}

In conclusion, dental caries, age and SCD severity were associated with a negative impact on the quality of life of parents of children with SCD.

\section{Acknowledgments}

This study received the support of the National Council for Scientific and Technological Development (Conselho Nacional de Desenvolvimento Científico e Tecnológico - CNPq), the Coordination for the Improvement of Higher Education Personnel (Coordenação de Aperfeiçoamento do Pessoal de Nível Superior - CAPES), the Lemann Foundation and Fundação Centro de Hematologia e Hemoterapia de Minas - Hemominas.

6. Barakat LP, Patterson CA, Daniel LC, Dampier C. Quality of life among adolescents with sickle cell disease: mediation of pain by internalizing symptoms and parenting stress. Health Qual Life Outcomes. 2008;6:60. doi:10.1186/1477-7525-6-60

7. Silva LBL, Ivo ML, Souza AS, Pontes ERJC, Pinto AMAC, Araujo OMR. The burden and quality of life of caregivers of sickle cell anemia patients taking hydroxyurea versus those not taking hydroxyurea. Rev Bras Hematol Hemoter 2012;34(4):270-4. doi:10.5581/1516-8484.20120070

8. George LK, Gwyther LP. Caregiver well-being: a multidimensional examination of family caregivers of demented adults. Gerontologist. 1986;26(3):253-9. doi:10.1093/geront/26.3.253

9. Panepinto JA. Health-related quality of life in sickle cell disease. Pediatr Blood Cancer. 2008;51(1):5-9. doi:10.1002/pbc.21557

10. Locker D, Jokovic A, Stephens M, Kenny D, Tompson B, Guyatt G. Family impact of child oral and oro-facial conditions. Community Dent Oral Epidemiol. 2002;30(6):438-48. doi:10.1034/j.1600-0528.2002.00015.x 
11. Abanto J, Paiva SM, Raggio DP, Celiberti P, Aldrigui JM, Bönecker M. Theimpact of dental caries and trauma in children on family quality of life. Community Dent Oral Epidemiol. 2012 Aug;40(4):323-31. doi:10.1111/j.1600-0528.2012.00672.x

12. Hemominas: Plano Diretor Estadual de Sangue e Hemoderivados [Internet]. Belo Horizonte: Homoninas; 2012 [cited 2014 Sep 12]. Available from: http://www.hemominas.mg.gov.br

13. World Health Organization. Oral Health Surveys: basic methods. 4th ed. Geneva: World Health Organization, 1997.

14. Jokovic A, Locker D, Stephens M, Kenny D, Tompson B, Guyatt G. Validity and reliability of a questionnaire for measuring child oral-health-related quality of life. J Dent Res. 2002;81(7):459-63. doi:10.1177/154405910208100705

15. Goursand D, Paiva SM, Zarzar PM, Pordeus IA, Allison PJ. Family Impact Scale (FIS): psychometric properties of the Brazilian Portuguese language version. Eur J Paediatr Dent. 2009;10(3):141-6.

16. Moynihan P, Petersen PE. Diet, nutrition and the prevention of dental diseases. Public Health Nutr. 2004 Feb;7(1A):201-26. doi:10.1079/PHN2003589

17. Flinck A, Källestal C, Holm AK, Allebeck P, Walls S. Distribution of caries in 12-year-old children in Sweden. Social and oral health-related behavioural patterns. Community Dent Health. 1999;16(3):160-5.

18. Pizzo G, Piscopo MR, Matranga D, Luparello M, Pizzo I, Giuliana G. Prevalence and socio-behavioral determinants of dental caries in Sicilian schoolchildren. Med Sci Monit. 2010;16(10):PH83-9.

19. Casey RL, Brown RT. Psychological aspects of hematologic diseases. Child Adolesc Psychiatr Clin N Am. 2003;12(3):567-84. doi:10.1016/S1056-4993(03)00025-7

20. Mahdi N, Al-Ola K, Khalek NA, Almawi WY. Depression, anxiety, and stress comorbidities in sickle cell anemia patients with vaso-occlusive crisis. J Pediatr Hematol Oncol. 2010;32(5):345-9. doi:10.1097/MPH.0b013e3181d869d5

21. van den Tweel XW, Hatzmann J, Ensink E, van der Lee JH, Peters M, Fijnvandraat K, et al. Quality of life female caregivers of children with sickle cell disease: a survey. Haematologica. 2008;93(4):588-93. doi:10.3324/haematol.11610
22. Palermo TM, Schwartz L, Drotar D, McGowan K. Parental report of health-related quality of life in children with sickle cell disease. J Behav Med. 2002;25(3):269-83. doi:10.1023/A:1015332828213

23. Panepinto JA, Hoffmann RG, Pajewski NM. The effect of parental mental health on proxy reports of health-related quality of life in children with sickle cell disease. Pediatr Blood Cancer. 2010;55(4):714-21. doi:10.1002/pbc.22651

24. Jokovic A, Locker D, Stephens M, Guyatt G. Agreement between mothers and children aged 11-14 years in rating child oral health-related quality of life. Community Dent Oral Epidemiol. 2003;31(5):335-43. doi:10.1034/j.1600-0528.2003.00012.x

25. Eiser C, Morse R. Can parents rate their child's health-related quality of life? Results of a systematic review. Qual Life Res. 2001;10(4):347-57. doi:10.1023/A:1012253723272

26. Midence K, FuggleP, Davies SC. Psychological aspects of sickle cell disease (SCD) in childhood and adolescence: a review. $\mathrm{Br}$ J Clin Psychol. 1993;32(3):271-80. doi:10.1111/j.2044-8260.1993. tb01057.x

27. Gift HC, Reisine ST, Larach DC. The social impact of dental problems and visits. Am J Public Health. 1992;82(12):1663-8. doi:10.2105/AJPH.82.12.1663

28. Anderson HK, Drummond BK, Thomson WM. Changes in aspects of children's oral health-related quality of life following dental treatment under general anesthesia. Int J Paediatr Dent. 2004;14(5):317-25. doi:10.1111/j.1365-263X.2004.00572.x

29. Onyeaso CO, DaCosta OO. Dental aesthetics assessed against orthodontic treatment complexity and need in Nigerian patients with sickle-cell anemia. Spec Care Dentist. 2009;29(6):249-53. doi:10.1111/j.1754-4505.2009.00104.x

30. Costa CP, Carvalho HL, Thomaz EB, Sousa SF. Craniofacial bone abnormalities and malocclusion in individuals with sickle cell anemia: a critical review of the literature. Rev Bras Hematol Hemoter. 2012;34(1):60-3. doi:10.5581/15168484.20120016 